\title{
Labordiagnostik der Pilzvergiftungen unter besonderer Berücksichtigung der Vergiftungen mit dem Knollenblätterpilz Amanita phalloides
}

\author{
MARIA KLA WITTER und WANDA LASOTA
}

\begin{abstract}
KLAWITTER, M. \& LASOTA, W. 1978: Labordiagnistik von Pilzvergiftungen unter besonderer Berucksichtigung der Vergiftungen mit dem Knol lenblytterpilz Amanita phalloides. - Karstenia 18 (suppl.).

Beschrieben wurden auch Eigenschaften der unterschiedlichen Sporen des Knollenblyt+erpilzes (Amanita phalloides) und andere Elemente, die sich im untersuchten Material von Kranken, wie Epithelzellen, Starkekörnchen, Fettropfen, Muskel fasern u.a., befanden. Zur Bestatigung der sporologischen Analyse wurde das biologische Material (Harn, Erbrochene, Dialyse der kunstl ichen Nierel bei Personen, die vergiftet waren, durch Ánwendung der Dunnschicht-Chromatographie untersucht.

Toxische Substanzen des Knollenblatterpilzes wurden vor allem im Urin nachgewiesen. Das Ziel einer biologischen Untersuchung von Ratten war, die Zeit genau zu bestimmen, in der die Ratten giftigen Substanzen des Knollenblatterpilzes ausscheiden.

Anhand dieser Untersuchungen wurde festgestellt, dass man das Vorkommen dieserchemischen Verbindungen im Urin und im Serum innerhalb von 7 Tagen nachweisen kann.

M. Klawitter, Sanitäts-Epidemiologische wojewodschaftsstation in Poznañ, Polen. w. Lasota, Anstalt der Bromatologia des Instituts für Unweltforschung und Bioanalyse der Medizinischen Akademie in Lódż, Polen.
\end{abstract}

Häufige Pilzvergiftungen in Polen und insbesondere Vergiftungen mit dem Knollenblätterpilz Amanita phalloides, die mit dem exitus letalis enden, haben uns veranlasst, Untersuchungen durchzufuhren, deren Ziel die Ausarbeitung eines systematischen und möglichst schnellen diagnostischen Verfahrens war.

Die Pilzvergiftungen sind im Anfangsstadium schwer diagnostizierbar, eine fruhe Diagnose der Vergiftungsursache spielt dagegen eine sehr wichtige Rolle besonders dann, wenn eine Knollenblatterpilzvergiftung in Frage kommt. Eine rechtzeitige Diagnose kann dann die richtige Behandlung sicherstellen.

In den Jahren 1964-1972 wurden 1247 Proben des biologischen, von pilzvergifteten Personen kommenden Materials untersucht. Es wurde nachgewiesen, dass das in der ersten Stunden seit Erscheinung derVergiftungssymptome gesammelte Erbrochene den grössten diagnostischen Wert darstellt.

Das Erbrochene enhält nämlich Speisereste, darunter auch Pilzreste und deren Sporen. Im Spulicht des ersten und spätestens des zweiten Tages sind auch Sporen zu finden, vorausgesetzt, dass der Mageninhalt nicht zu sehr verdünt ist.

Die Beobachtungen haben erwiesen, dass bei Identifizierung der Pilzvergiftungen die sichergestellten unverbrauchten Speisereste eine begunstigende Rolle spielen können.

Bearbeitet wurde ein Schema der makroskopischen Analyse von unverbrauchten Speiseresten und Erbrochenem.
Die makroskopische Analyse besteht - unabhängig von der Art des Materials - in der Abtrennung der festèn Teile von den flussigen mittels Filtration durch Sieb oder Mull. Wenn die Speise viel Fett enthält, ist die Entfettung mit einer Mischung von äthyl- und Petroläther unentbehrlich.

Die abgetrennten Fruchtkörper oder ihre Fragmente werden makroskopisch mit binokulärer Lupe oder analytischer Lampe analysiert. Dabei wird auf den Bau des Hymenophors, die Form der Lamellen und die Fluoreszenz geachtet.

Der flussige Teil wird dagegen mikroskopisch auf das Auftreten von Sporen untersucht.

Die sporologische Analyse wurde mit Vorbereitung einer Kollektion reiner Mustersporen von essbaren und giftigen Pilzen begonnen.

Die Sporen von reifen Fruchtkörpern wurden durch Ausschuttung, die Sporen von Fruchtkörpern dagegen in verschiedenen Reifestadien nach der Ertmannschen Methode gewonnen. Zur Erlangung eines reellen Bildes, das die Identifizierung der im biologischen Material befindlichen Sporen ermöglichen würde, prufte man sie in natürlichem Zustand, dann nach Einwirkung von $10 \%$ - iger Salzsäurelösung mit Zusatz von Pepsin und nach Kochen in Wasser.

Zur besseren Differenzierung der Sporen wurde die Färbung der Präparate nach einfachen und kombinierten, in der mikroskopischen Analyse benutzen Methoden angewendet. Es wurde festgestellt, dass die 
Farrbung nach einfachen Methoden nur schwach kontrastiert. Gute Resultate erzielte man nach den kombinierten Methoden. Man stellte fest, dass die sporen von A.phalloides und Russula aeruginea, nach der Methode von Schäfer-Fulton gefarbt, rosa oder rot werden, wobei die Farbe der Hüllen intensiver ist.

Die gelben oder gelb-braunen Sporen blieben gelb, nur die Hülen wurden rot. Die Färbung nach der Methode von Ziehl-Neelsen erwies, dass die Sporen der Amanita species und $R$. aeruginea leicht blau, und die Hüllen intensiv blau gefärbt werden. Die Sporen von Naematoloma fasciculare, Inocybe patouizzardi und Gyromitra esculenta wurden rosa, violett, oder rosaviolett mit intensiv gefärbten Hullen.

Die Sporen von Paxilzus involutus, Macrolepiota procera und Boletus edulis färbten sich schwach blau und die Hüllen blieben ungefärbt.

Es wurden auch Beobachtungen der Sporen in polarisiertem Licht und im Licht der UV-Strahlen mit dem Wood-Filter durchgefunrt.

Man bemerkte, dass das Endosporium und das Episporium mancher Sporen im UV-Licht fluorisieren. Dann ist die ausdrückliche Form der Sporen dunklen Lichtfeld sichtbar. Von den untersuchten Gattungen zeigten die Sporen von Amanita Species, $R$. aeruginea, Agaricus campestris, $M$. procera und Tricholoma flavovirens keine Fluoreszenz.

Zur Erlangung eines ausdrücklichen Bildes der Sporen besonders von A. phalloides und zur Unterscheidung derselben von anderen Begleitelementen wurden bei den Beobachtungen Luminophore angewandt.

Man erhielt folgendes Sporenbild von A,phazloides. Die Sporen gehen wegen ihrer grossen Widerstandsfähigkeit gegen die Wirkung der Magensăure in fast unverändertem Zustand in den Kot uber. Der Kot kann deswegen auch als das diagnostiche Material bei Pilzver- giftungen gelten. Die Analyse des Kots besteht in der Hydrolyse der Kotmasse und Isolierung der Sporen, die in dieser Situation nicht ihre diagnostischen Eigenschaften verlieren.

Um die sporologische Analyse zu bekrätigen, untersuchte man das biologische, von vergifteten Personen stammende Material mittels der dünschichtigen Chromatographie, wobei man sich auf Untersuchungen von Willand stutzte.

Es wurde die chromatographische Analyse des konzentrierten biologischen Materials von 35, mit dem Knollenblatterpilz vergifteten Personen durchgefürt.

Man untersuchte den Harn, das Erbochene und die Dialysate aus der Kunstniere. Das Vorkommen von toxischen Stoffen wurde in 31 Harnproben nachgewiesen. Die erzielten Ergebnisse weisen darauf hin, dass im Falle einer Knollenblättervergiftung die toxischen Stoffe vor allem im Harn vorkommen und auf diesem Wege ausgeschieden werden.

Zuletzt fuhrte man biologische Untersuchungen an Ratten durch. Das Ziel war, die Zeitdauer des Entfernens der toxischen Substanzen des Knollenblätterpilzes durch den Organismus zu bestimmen.

Es handelte sich um die Bestimmung der Zeitspanne, während der die Möglichkeit besteht, das Vorkommen von toxischen Substanzen in den Flussigkeiten des Organismus chemisch nachzuweisen. Die Beobachtungen erwiesen, dass das Vorkommen toxischen Verbindungen des Knollenblatterpilzes in Harn und Blutserum der Ratten nach dem dargestellten chromatographischen Verfahren innerhalb von 7 Tagen nachweisbar ist. Im Blutserum der beobachteten Tiere (Ratten) kamen Phalloidine und Amanitine vor;im Harn kam nur Phalloin, und am vierten Tage Phalloidin vor Amanitine wurden nicht nachgewiesen. 